\section{Анализ технологии заготовки сортиментов в процессе лесосечных работ ${ }^{1}$}

\author{
Ю. А. Ширнин ${ }^{2}$ \\ Марийский государственный технологический \\ университет
}

\begin{abstract}
АННОТАЦИЯ
В статье дан анализ 6 систем лесосечных машин для заготовки сортиментов. Выявлены границы их применимости. Показаны основные характеристики технологии использования, обозначены преимущества и недостатки. Предложена схема поиска эффективного применения систем машин в различных условиях.
\end{abstract}

Ключевые слова: сортимент, система машин, технология, эффективность, управление, критерии.

\section{SUMMARY}

In this article the analysis of 6 forest machine systems for short-length technology is given, and the limitations of their effective use are discovered. Principal characteristics of technology use are shown, the advantages and disadvantages are indicated. The scheme to search the efficient application of forest machine systems in different conditions is offered.

Keywords: assortment, machine system, technology, effectiveness, direction, criteria.

\section{ПОСТАНОВКА ПРОБЛЕМЫ}

На лесозаготовках в РФ произошли и происходят кардинальные изменения, связанные с дроблением крупных государственных предприятий на предприятия с небольшим объемом производства, со сменой формы собственности, с присоединением лесозаготовок к деревообрабатывающим производствам: фанерным, целлюлозно-бумажным, гидролизным, мебельным и т.д. Происходит изменение сложившейся структуры лесозаготовок: лесосечных работ, транспорта леса, лесоскладских работ. Постепенно операции лесоскладских работ перемещаются на лесосеку, а доля доминирующей многие десятилетия технологии лесозаготовок с вывозкой хлыстов уменьшается в основном за счет возрастания доли вывозки сортиментов, особенно в Европейской части страны.

Современный инвестор ориентируется главным образом на выпуск товарной продукции, с тем, чтобы как можно быстрее окупить вложенный капитал. Во время процесса накопления капитала нецелесообразно создавать крупные предприятия, тем более, что и

\footnotetext{
${ }^{1}$ Исследования по материалам данной статьи проведены при финансовой поддержке Министерства образования Российской Федераџии

2 Автор - профессор кафедры технологии и оборудования лесопромышленных производств

(C) Ю. А. Ширнин, 2003
}

лесфонд Европейской части РФ не дает такой возможности во многих регионах.

Таким образом, число предприятий с малым объемом лесозаготовок будет расти и перед ними будет вставать вопрос о том, в каком виде целесообразнее вывозить древесину с лесосеки - в хлыстах или сортиментах. В книге [1] определены основные признаки малообъемных лесозаготовок.

\section{ОБЪЕКТ ИССЛЕДОВАНИЙ}

Объектом исследования являются технологические процессы лесосечных работ с вывозкой сортиментов. Возможные варианты комплектов машин для выполнения этого процесса и их технико-экономические параметры представлены в таблице. Расчет годовой выработки выполнен при числе рабочих дней в году, равном 250 .

В системах 1, 4 раскряжевка производится у пня и, следовательно, трелюются сортименты. В системах 2, 3 трелевка осуществляется деревьями, очистка от сучьев и раскряжевка которых выполняются на верхнем складе. В системах 5, 6 при раскряжевке на погрузочном пункте трелевка может быть как деревьями, так и хлыстами.

Следует иметь в виду, что в системах машин 4,5 и 6 в 2-3 смены работают лишь ведущие машины (на сборе и трелевке). Валка, обрезка сучьев и раскряжевка могут выполнятся в запас - с меньшим числом смен, но с большим числом рабочих звеньев.

\section{АНАЛИЗ СПОСОБОВ ЗАГОТОВКИ СОРТИМЕНТОВ}

В течение последних десятилетий в области машинной заготовки сортиментов значительный прогресс достигли Скандинавские страны (Швеция и Финляндия). На мировой рынок поставляются харвестеры и форвардеры таких фирм, как VALMET, PONSSE, TIMBERJACK и другие.

Предлагаемые ими системы машин (харвестер + форвардер) существенно упрощают машинный технологический процесс лесозаготовок. Добавление к ним рубительной машины дает возможность очищать лесосеку и подготавливать ее к лесовыращиванию. При этом полностью выполняется процесс лесозаготовок от подготовительных до заключительных работ, нет необходимости в сооружении лесопромышленных складов. Сортиментная вывозка и разработанные системы машин позволяют до минимума сократить переместительные операции. Отпадает необходимость в предельно энергонасыщенных шасси, т.к. раскряжевка у пня исключает необходимость подъема-погрузки целых стволов при выполнении последующих операций.

Технологическая оснастка машин, включающая манипулятор с харвестерной головкой (захват, срезание, обрезка сучьев, отмер длин, раскряжевка и сортировка), выполнена компактно и надежно, одинаково применима на сплошных и выборочных рубках. Компановка технологического оборудования и кабины 
управления харвестеров, позволяющая вести разработку лент по фронту движения машины, дает возможность применять рациональную челночную схему освоения лесосеки. При этом сведены к минимуму холостые ходы, сберегаются энергоресурсы, повышается производительность машин. Отдельные конструкции харвестеров используют экскаваторную базу со снятием дерева с пня и полным восприятием силы тяжести дерева. Чаще используется метод валки сталкиванием срезанного дерева с пня.

При этом низкое расположение основания поворотной колонны манипулятора и шарнирно-сочлененная рама шасси исключают необходимость применения аутриггеров против опрокидывания, установка и сня- тие которых значительно удлиняют время цикла обработки предмета труда.

Начавшееся развитие машин циклично-непрерывного действия (харвестеры ЛОКОМО 961Т, ЛОКОМО 961S, КОРИНГ КХЗ-Д, VALMET 448), у которых одновременно с обрезкой сучьев и раскряжевкой одного дерева выполнялась валка другого, приостановлено. Причиной этого является то, что выигрыш по времени за счет совмещения операций не компенсирует потери, связанные с увеличением массы и энергонасыщенности харвесторов цикличнонепрерывного действия, с одной стороны, и с другой - невозможно их использовать на выборочных и постепенных рубках.

Таблица

Технико-экономические параметры комплектов машин

\begin{tabular}{|c|c|c|c|c|c|c|c|}
\hline \multirow[t]{2}{*}{$\begin{array}{c}\text { № } \\
\Pi / \Pi\end{array}$} & \multirow[t]{2}{*}{ Комплект машин } & \multirow{2}{*}{$\begin{array}{l}\text { Производ. } \\
\text { базовой ма- } \\
\text { шины, м³/см }\end{array}$} & \multirow{2}{*}{$\begin{array}{c}\text { Стоимость } \\
\text { комплекта, } \\
\text { тыс. \$ США }\end{array}$} & \multicolumn{3}{|c|}{ 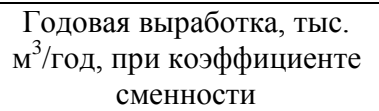 } & \multirow{2}{*}{$\begin{array}{c}\text { Число } \\
\text { обсл. } \\
\text { рабоч. в } \\
\text { смену }\end{array}$} \\
\hline & & & & 1 & 2 & 3 & \\
\hline 1 & ВСРМ + ПТМС & 92 & 660 & 23 & 46 & 69 & 2 \\
\hline 2 & ВПМ+ТМ+CPM & 90 & 113,928 & 22,25 & 44,5 & 66,75 & 3 \\
\hline 3 & BTM+CPM & 69 & 71,928 & 17,25 & 34,5 & 51,75 & 2 \\
\hline 4 & БП+ПТМС & 90 & 220,713 & 22,5 & 45 & 67,5 & 5 \\
\hline 5 & БП+ПТК+БП & 64 & 27,54 & 16 & 32 & 48 & 5 \\
\hline 6 & БП+ПТМ+БП & 78 & 56,713 & 19,5 & 39 & 58,5 & 5 \\
\hline
\end{tabular}

Примечания к таблице: ВСРМ - валочно-сучкорезно-раскряжевочная машина (харвестер); ПТМС - пакетировочнотрелевочная машина для сортиментов (форвардер); БП - бензопила; ТТК - трелевочный трактор с канатно-чокерным оборудованием (ТДТ-55А); ПТМ - пакетировочно-трелевочная машина (ТБ-1М); ВПМ - валочно-пакетирующая машина; ВТМ - валочно-трелевочная машина (ЛП-17А); ТМ - трелевочная машина (ЛТ-89Б); СРМ - сучкорезнораскряжевочная машина (ЛО -120)

Главной проблемой применения харвестеров и форвардеров на лесозаготовках России является их значительная стоимость. Приемлемый срок окупаемости такой системы машин возможен при 2-, 3-сменной работе в течение года. При норме выработки $92 \mathrm{~m}^{3} /$ смену на лесосеке со средним объемом хлыста в пределах $0,3-0,39 \mathrm{~m}^{3}$ и 250 рабочих дней годовая выработка харвестера составит от 46000 до $69000 \mathrm{~m}^{3}$.

В России были созданы харвестеры (МЛ-72, МЛ-20) собственного производства. Однако их технические характеристики неудовлетворительные и поэтому в настоящее время прорабатывается вариант с использованием отечественного шасси с навеской на него зарубежного манипулятора с харвестерной головкой (СОФИТ, МЛХ-424, МЛХ-324, харвестер на базе ЛП-19В). Их стоимость более приемлема для российских лесозаготовителей.

Машинный способ производства обеспечивают также системы 2 и 3. Они могут быть скомплектованы из машин отечественного производства, а поэтому более доступны. В этих системах трелевка осуществляется деревьями и поэтому весьма проблематичны сохранение подроста и возможность использования их на постепенных и выборочных рубках, а также на переувлажненных грунтах в летний период.
Наиболее приемлемой для отечественных лесозаготовителей является комбинированная система машин 4. Это тем более перспективно, поскольку на рынке появились российские форвадеры. Рынок предлагает также подержанные машины зарубежных фирм. Системы 5 и 6 представляют традиционную схему заготовки хлыстов и их раскряжевку бензопилами на верхнем складе с последующей ручной раскаткой в штабеля. Эти системы не требуют больших капитальных затрат и при наличии дешевой рабочей силы еще долгое время могут находить применение. Трелевка хлыстами вершинами вперед дает возможность успешно использовать эти системы на рубках главного и промежуточного пользования.

Отметим, что вывозка сортиментов имеет по сравнению с раскряжевкой на нижнем складе ряд недостатков.

Поставленная цель рационального раскроя для получения максимально возможного выхода качественных сортиментов не всегда обеспечивает рациональную загрузку форвадеров и автолесовозов. На практике чаще применяют ограниченное число выпиливаемых сортиментов, чем нельзя добиться максимального выхода деловой древесины. 
При вывозке сортиментов в лесу остается большое количество невостребованных отходов лесозаготовок, что ведет к захламлению вырубок.

Технология заготовки сортиментов в лесу требует доставки на лесосеку и обратно большого числа рабочих, что, впрочем, при малом объеме лесозаготовок не столь существенно.

\section{ЗАДАЧИ УПРАВЛЕНИЯ ПРИ ЗАГОТОВКЕ И} ВЫВОЗКЕ СОРТИМЕНТОВ. КРИТЕРИИ. МОДЕЛЬ

Управленческие решения принимаются в следующих условиях:

1. На предприятии имеется комплект лесосечных машин для заготовки сортиментов. При этом нет ограничений в аренде лесного фонда, в найме рабочей силы. Ставится задача нахождения предельно эффективного объема лесозаготовок без дополнительных затрат на приобретение оборудования;

2. Предприятие имеет в аренде лесной фонд с известным годовым объемом заготовки в пределах расчетной лесосеки. Средства на приобретение лесосечного оборудования и машин ограничены. Ставится задача выбора эффективного комплекта лесосечных машин для заготовки сортиментов;

3. Предприятие, накопив оборотные средства, планирует увеличить объем производства. Рынок рабочей силы не ограничен, так же как и предложения по аренде лесного фонда. В этой связи возникает несколько альтернатив:

а) увеличить объем производства за счет увеличения коэффициента сменности;

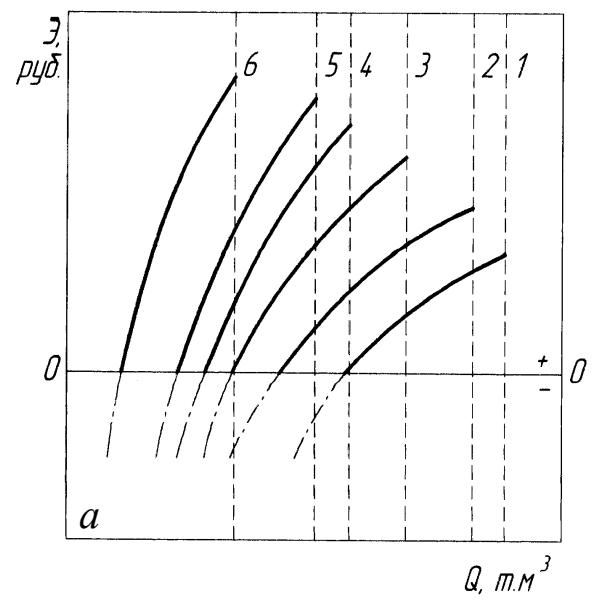

б) увеличить число комплектов машин, имеющихся на предприятии;

в) продать имеющийся комплект и, вложив дополнительные средства, приобрести более производительный.

В сформулированных задачах важнейшим параметром в принятии решения является годовой объем производства круглых лесоматериалов. При раскряжевке у пня либо на верхнем складе системами машин 1 - 6 (см. рис.) выход деловых сортиментов может быть разным. Поэтому будет различной средняя цена единицы объема выработанной продукции. Критерием, оценивающим эффективность принимаемых решений, может быть прибыль предприятия (Э, руб.).

Функционал показателя эффективности (Э, руб.) в общем виде может быть выражен следующим образом:

$$
Э=\Phi\left(\begin{array}{l}
И_{1}, И_{2}, \ldots, И_{\mathrm{n}} ; \\
\mathrm{X}_{1}, \mathrm{X}_{2}, \ldots, \mathrm{X}_{\mathrm{m}} ; \\
\mathrm{V}_{1}, \mathrm{~V}_{2}, \ldots, \mathrm{V}_{\mathrm{\kappa}}
\end{array}\right)
$$

При заданных условиях $И_{1}, И_{2}, \ldots, И_{\mathrm{n}}$ (параметры лесосечного фонда) с учетом неизвестных (предполагаемых) факторов $\mathrm{V}_{1}, \mathrm{~V}_{2}, \ldots, \mathrm{V}_{\mathrm{K}}$ (стоимость рабочей силы, цена на энергоносители и др.) следует найти элементы решения $\mathrm{X}_{1}, \mathrm{X}_{2}, \ldots, \mathrm{X}_{\mathrm{m}}$ (годовой объем заготовки, комплект лесосечных машин, коэффициент сменности и др.), которые по возможности обращали бы в максимум показатель эффективности Э.

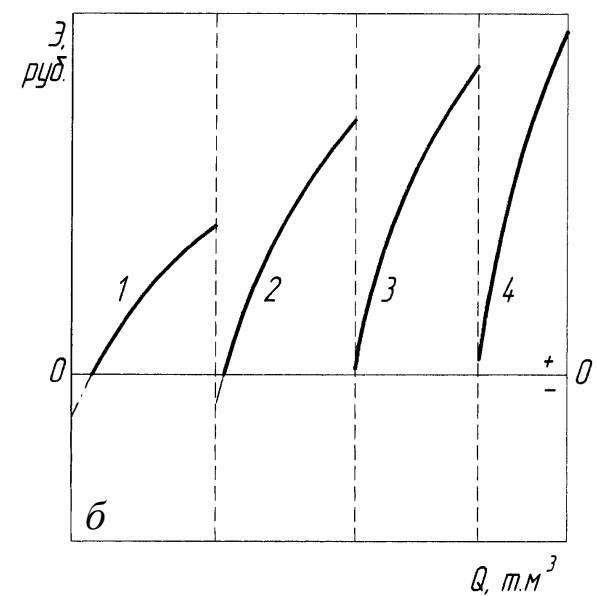

Рис. Характер зависимости эффективности использования систем машин (Э) от годового объема лесозаготовок $(\mathrm{Q})$ :

$a$-различные (1-6) системы машин, пунктирные линии 1-6- верхние границы использования систем машин; 6 - системы машин при наличии одного (1), двух (2), трех (3) и четырех (4) комплектов;

На рисунке представлены граничные значения годового объема заготовки сортиментов исходя из возможностей базовой машины (наиболее дорогостоящей и производительной при 1-, 2- и 3-сменной рабо- те). Среднегодовой коэффициент сменности может иметь значения, отличные от целочисленных. 
Характер зависимости эффективности использования систем машин (рис. $a$ ) от годового объема заготовки сортиментов и от числа комплектов системы машин (рис. б) представлен на рисунке.

Вертикальные пунктирные линии означают границы максимальной годовой выработки систем машин 1 6 (рис. a). Предполагается, что недорогие системы машин при низкой заработной плате рабочих при малых объемах производства более эффективны. Результат может быть иным при значительном повышении заработной платы.

\section{ВЫВОДЫ}

1. Для малообъемных лесозаготовок технологический процесс с вывозкой сортиментов является предпочтительным по сравнению с вывозкой хлыстов.

2. Применение механизированных систем машин на заготовке сортиментов в малых объемах вполне оправдано в период накопления оборотных средств и наличия дешевой рабочей силы.
3. В ближайшей перспективе в РФ найдет применение система машин 4, обеспечивающая заготовку сортиментов при выполнении различных способов рубок.

4. Применение системы машин 1 при значительных объемах производства целесообразно при высокой заработной плате рабочих.

5. Конкретные границы эффективной применимости систем машин могут быть получены в процессе решения изложенных задач и их оптимизации по предлогаемой методике.

\section{СПИСОК ЛИТЕРАТУРЫ}

1. Ширнин Ю. А., Пошарников Ф. В. Технология и оборудование малообъемных лесозаготовок и лесовосстановление: Учебное пособие. Йошкар-Ола: Издво МарГТУ, 2001. 398 с. 